\title{
El Estado y la modernización de la administración de justicia en una economía de mercado
}

Carlos Ramón Noda Yamada

\section{Introducción}

En el presente trabajo se realiza un estudio sobre la relación entre el Estado y la administración de justicia, su evolución en el Perú, y su posible modernización.

Planteamos en este ensayo un modelo de Estado basado en la eficiencia como alternativa u objetivo para lograr el progreso, el desarrollo, la justicia y la equidad reales, concretas y tal como son posibles en este mundo. Todo este modelo descansa en un frío y desapasionado análisis: el objetivo tiene que ser la eficiencia, y sólo la eficiencia. No pueden ser objetivos nociones ideales de justicia y equidad, pues seguirlas ya ha llevado al fracaso y a la pobreza a muchos pueblos latinoamericanos, entre ellos el Perú; esto no significa que dejemos de lado a la justicia y equidad como productos reales y concretos. La justicia y la equidad concretas se producirán como efecto o consecuencia de la eficiencia, y se producirán no en un nivel perfecto, sino, en la medida de lo posible en un mundo imperfecto y con recursos escasos como el nuestro.

Este modelo utiliza el enfoque económico del comportamiento humano, el análisis económico del Derecho, y todas las poderosas herramientas científicas y comprobables que pone a nuestra disposición la moderna ciencia económica. Creemos por sobre todo que el objetivo final de todo lo existente debe ser la eficiencia, y que todo problema puede ser juzgado y resuelto en base al criterio de eficiencia, estando subsumido todo otro concepto o idea dentro de este criterio. 
Debemos advertir que este modelo no pretende ser una solución mágica y absoluta, ni pretende ser una imposición; solamente representa lo que creemos que debe ser el Estado. Esto es consecuente con la base material constituida por la libertad. Nuestro enfoque tiene como ejes centrales a la libertad y a la información para justificar la existencia del Estado según el criterio de eficiencia; veremos que un Estado eficiente es necesario para tener un mercado eficiente que permita la maximización racional de la utilidad de los individuos.

Este estudio está dividido en tres capítulos que van avanzando en el desarrollo del tema en distintos niveles. El primero es un planteamiento teórico sobre la administración de justicia y su relación con la totalidad del Estado desde el punto de vista del análisis económico del derecho. El resultado es nuestro modelo de Estado y administración de justicia en la economía de mercado.

El segundo es un análisis histórico de la problemática de la administración de justicia en el Perú, relacionada con la problemática total del Estado y la sociedad peruana desde su independencia del imperio español. El resultado es el descubrimiento de la corrupción generalizada de la sociedad peruana como responsable de la crisis del Estado y la administración de justicia. Una corrupción entendida no en la forma tradicional como la falta de valores morales, sino según el enfoque económico del comportamiento humano como una toma de decisiones inadecuadas e ineficientes debido a información escasa y errónea, es decir, la corrupción es el resultado de un intento de maximizar racionalmente la propia utilidad en función a una base de datos inadecuada de una falsa apreciación de la realidad.

El tercero es un planteamiento de los objetivos, requisitos y modos de llevar a cabo una reforma integral de la administración de justicia y el Estado en una economía de mercado. Aquí se establece nuestro concepto particular de lo que es una economía de mercado, sus efectos liberadores, y el rol que deben cumplir el Estado y la Administración de justicia en esta nueva era.

\section{El Individualismo y el rol del Estado}

En el presente capítulo buscaremos establecer nociones básicas del análisis económico del Derecho, para aplicarlas a la construcción de 
modelo de Estado y de administración de justicia basados en el postulado de eficiencia y en el individualismo metodológico.

\subsection{Nociones preliminares}

A nuestro entender existen dos maneras de abordar el problema del rol del Estado. La primera es asumir un criterio organicista, según el cual, la sociedad es tratada como si fuera un ente vivo con voluntad independiente, y el Estado es idealizado y tomado como una unidad política con voluntad independiente de los individuos que lo componen; esta es la forma como se ha enfocado al Estado la mayoría de las veces. La segunda forma de tratar este problema parte de un criterio individualista, según el cual, la sociedad y el Estado están formados por individuos, cada uno de los cuales busca su propio bienestar ${ }^{1}$.

Nosotros nos decidimos claramente por la segunda vía, ya que la consideramos la más adecuada para lograr llegar a conclusiones y propuestas coherentes y que superen con éxito una confrontación con la realidad.

Rechazamos una visión organicista de la sociedad y del Estado porque asumirla o aceptarla significaría introducir nociones gaseosas y de muy difícil o imposible comprobación científica; estamos hablando de nociones como la "voluntad general" de la sociedad, independiente de la voluntad de los individuos, o que existe un "bien común" como verdad general y absoluta al que la sociedad está encaminada ${ }^{2}$. Para nosotros, lo único que existe es la voluntad de los individuos y un bienestar individual que cada individuo trata de maximizar.

El bienestar social será, para este enfoque, el bienestar de cada uno de los individuos que componen la sociedad; y las decisiones del Estado serán resultado, también, del comportamiento de los individuos que integran los centros de toma de decisiones ${ }^{3}$. La única realidad tangible es la existencia de individuos distintos entre sí, cada uno con su propia voluntad y con sus propios intereses - no son distintas preferencias, pues las preferencias son estables entre los individuos, como lo explicaremos más adelante.

\footnotetext{
James Buchanan y Gordon Tullock. The Calculus of Consent. p. 11-14.

Loc.cit.

Juan Torres López. Análisis Económico del Derecho. p.30.
} 
Según el criterio individualista los individuos son interesados y tratan de maximizar su bienestar -maximizar racionalmente su propia utilidad-, para lo cual su comportamiento es racional, entendiendo por racionalidad la elección consistente entre aquellas alternativas que le resultan mejores entre las que se encuentran a su disposición. Esta maximización racional no debe ser confundida nunca con un cálculo consciente ni con el egoísmo ${ }^{4}$; solamente se refiere, como lo hemos expresado, a una conformidad con un modelo consistente de elección racional, cualquiera que sea el estado de animo del individuo ${ }^{5}$.

Como consecuencia del postulado individualista se deriva el principio de estabilidad de las preferencias de los individuos, según el cual, si las preferencias cambian, habría de entenderse que las elecciones previamente efectuadas carecen de consistencia generándose, de esta manera, una contradicción con el presupuesto de la conducta racional de los individuos. Los gustos o las preferencias son invariables, jamás cambian caprichosamente o difieren sorprendentemente entre los individuos $^{6}$. Los precios y otros instrumentos de mercado asignan los recursos escasos dentro de cada sociedad -siempre que se hable de sociedad debe entenderse a la sociedad como conjunto de individuos-, poniendo limitaciones a los deseos de los participantes en ese mercado y coordinando sus acciones. Las preferencias estables no se refieren a los bienes y servicios del mercado, sino a los objetos subyacentes a la elección, que son producidos por cada consumidor utilizando los bienes y servicios del mercado, junto con su propio tiempo y otros factores. Estas preferencias subyacentes están definidas respecto de aspectos

4 Generalmente se dice que la Teoría de la Elección Pública es una teoría que predica que los individuos son egoístas maximizadores racionales de su utilidad. Esto es falso, la conciencia racional no significa egoísmo ni altruismo, incluso creo que la conciencia racional es la mejor defensa de la justicia, la equidad y la libertad concretas, como espero demostrarlo a lo largo de este ensayo.

5 Véase: Gary S. Becker. "Irrational Behavior and Economic Theory" p. 1. En Journal of Political Economy. Vol 70, N 1; Santos Pastor. "Una introducción al análisis económico del Derecho" p. 157-158. En Hacienda Pública Española, 1984; Richard A. Posner. Economic Analysis of Law. 4a.ed. Boston: Little, Brown and Company, 1992. P.3-4; Richard A. Posner. The Economics of Justice. Cambridge: Harvard University Press, 1981. P.1; y Juan Torres López. Op.cit., p.30-31.

6 Véase al respecto: George J. Stigler y Gary S. Becker. "De Gustibus Non Est Disputandum" p.76. En American Economic Review. March 1977. Vol. 67 N $^{\circ} 2$; y Juan Torres López. Op.cit., p.32. 
fundamentales de la vida, que no siempre guardan una relación estable con los bienes y servicios del mercado ${ }^{7}$.

\subsection{Intervención estatal y eficiencia}

El enfoque económico individualista que hemos asumido supone la existencia de mercados que, con distinto grado de eficiencia, coordinan las acciones de los distintos agentes que participan en ellos, de forma que su comportamiento resulta mutuamente consistente. Nuestro enfoque tiene como factor fundamental la escasez, entendida como elemento permanente, por lo que la tarea de la Economía y del Derecho es ser, complementariamente, las ciencias de la elección racional en un mundo en el que los recursos son limitados en relación con las necesidades humanas ${ }^{8}$. La escasez y la definición del hombre como maximizador racional de su utilidad nos llevan a la necesidad de analizar el criterio de eficiencia y su relación con la intervención estatal.

La eficiencia alude a la relación entre los beneficios totales de una situación y los costes totales de la misma, en un sentido lato. En sentido estricto, nos estamos refiriendo al criterio u óptimo de eficiencia de Pareto, según el cual, una situación se ajusta a la eficiencia si no hay ningún cambio posible de esa situación que pueda mejorar la situación de alguien sin empeorar al mismo tiempo la de otro. En otras palabras, la eficiencia económica requiere que se escoja el conjunto de titularidades que llevaría a una distribución de recursos que no pueda ser perfeccionada, en el sentido que un cambio adicional no mejoraría la condición de aquellos que perdieron con la misma y permanecer aún en mejores condiciones que antes.

En la situación de equilibrio que representa el óptimo de Pareto, los bienes y factores productivos tienden a gravitar en torno a su mejor $y$ más eficiente uso posible; y bajo estas hipótesis, el Derecho debe limitarse exclusivamente a garantizar más función de intervención. En este punto es preciso dejar en claro una idea: se trata de establecer que el

7 Gary S. Becker "El Enfoque Económico del Comportamiento Humano” p.20. En Información Comercial Española. N 557 Enero 1980.

8 Sobre el tema véase: Gary S. Becker "El enfoque económico...". En loc.cit.; Douglass C. North. Estructura y cambio en la historia económica. P.18; y Richard A. Posner. Economic Analysis of Law. p.3. 
concepto de eficiencia contiene una serie de valores humanos y morales concretos -no idealizados-, y que es parte de la noción común de justicia? .

Para que pueda darse el óptimo de Pareto es requisito indispensable que los costes sociales que se derivan de todas y cada una de las actividades que se realizan en el mercado sean iguales a los beneficios sociales. Pigou demostró, sin embargo, que es muy probable que se dé una divergencia entre ambos; son los casos de las "diseconomías externas" o "externalidades" y que ponen de manifiesto la inconsistencia del mercado como instrumento exclusivo para alcanzar la eficiencia social. En este caso sería el Estado quien debería intervenir para corregir los fallos del mercado a través del mecanismo coercitivo del Derecho. Esta última afirmación merece ser analizada con cuidado y sirve para introducir el Teorema de Coase.

Ronald Coase propuso una idea básica del análisis económico en un artículo escrito en $1960^{10}$. Según el teorema de Coase, el Estado deberá intervenir si los beneficios netos de su actuación son mayores que los de su no intervención.

El Estado solamente deberá intervenir cuando los beneficios netos de su actuación sean mayores que los de su no intervención; es decir, cuando debido a los costes de transacción y a la presencia de externalidades, la solución eficiente no pueda alcanzarse sin la asignación de la titularidad del derecho por una norma jurídica emanada de él.

Estas afirmaciones anteriores tienen que ser tomadas en sentido estricto para constituir una adecuada base de información. No estamos apelando al conocido argumento de la regulación y de la protección de los individuos por el Estado. Esto no pasó jamás por nuestro pensamiento, pues la regulación excesiva y el proteccionismo son ineficientes

9 Sobre la eficiencia pueden verse: Alfredo Bullard. " $\mathrm{Al}$ fondo hay sitio! ¿Puede el Teorema de Coase explicarnos el problema del Transporte Público?" p.94 En Thémis N²1; Guido Calabresi. "First Party, Third Party, and Producto Liability System: Can Economic Analysis of Law Tell Us Anything About Them?" p.834 En Lowa Law Review. Vol. 69 May 1984; Guido Calabresi y Douglas Melamed "Reglas de la Responsabilidad e Inalienabilidad: Un vistazo a la Catedral" p.66 En Thémis No21; Santos Pastor. Op.cit., p. 158; A. Mitchell Polinsky . Introducción al Análisis Económico del Derecho. p.19; Juan Torres López. Op.cit., p.26.

Una discusión sobre el óptimo de Pareto puede revisarse en: Posner, Richard A. Economic Analysis of Law. p.12-16.

10 Ver: Ronald Coase. "The Problem of Social Cost" En Journal of Law and Economics. Vol. 31960. 
en extremo. El verdadero rol del Estado es garantizar la eficiencia del mercado, para lo cual debe apuntar él mismo a la eficiencia. Esto significa que el Estado solamente debe intervenir para reducir los costes de transacción y lograr la eficiencia del mercado y la asignación de los recursos a su mejor uso-como consecuencia del funcionamiento de ese mercado eficiente-. El libre y eficiente juego del mercado produce el bienestar de los individuos, no la regulación y la intervención estatal. El Estado solamente es un garante de la libertad y los derechos de cada individuo; estos derechos de los individuos asignados por las normas jurídicas son los mínimos necesarios según el Teorema de Coase. Jamás debe entenderse que el rol del Estado sea proteger, pues pensar esto sería contradictorio con la eficiencia y la defensa de la libertad.

\section{3. ¿Qué es la administración de justicia?}

Se puede decir que la administración de justicia es un equivalente a hablar de tribunales, jurisdicciones, o Poder Judicial. Según esto, la administración de justicia estaría compuesta por los órganos del Estado que aseguran la aplicación de las reglas de derecho establecidas por los gobernantes ${ }^{11}$. La administración de justicia sería portadora del poder jurisdiccional, es decir, del poder de definir el derecho.

Es aceptable hablar en esos términos de la administración de justicia, en realidad es opinión mayoritaria en la doctrina, salvo opiniones que, apuntando más al significado de las palabras, hacen una distinción entre "Administración de Justicia" como concepto vinculado a una subordinación de la función jurisdiccional al Poder Ejecutivo, y "Poder Judicial" como órgano independiente encargado de definir el derecho ${ }^{12}$. Para nuestro estudio, estas disquisiciones meramente teóricas no tienen ninguna relevancia.

Hemos dicho que entender a la administración de justicia como órgano del Estado que asegura la aplicación de las reglas de derecho establecidas por los gobernantes y portadora, por tanto, del poder jurisdiccional, es correcto. Pero hay mucho más en el fondo, hay una

11 Maurice Duverger. Instituciones políticas y derecho constitucional. 5a. de. Barcelona: Ariel, 1970 p. 158.

12 Juan Montero Aroca y Manuel Ortells Ramos. Derecho Jurisdiccional. Parte General. Barcelona: Librería Bosch, 1987. p. 45-52. 
mejor manera de definir a la administración de justicia y denotar su verdadera naturaleza; podemos decir que la administración de justicia es esencialmente un servicio. Este servicio es prestado por el Estado a la comunidad mediante la solución de controversias para mantener la paz social y facilitar el desarrollo económico.

\subsection{Funciones de la administración de justicia}

Se ha hablado bastante acerca de la importancia y las funciones de la administración de justicia; por ejemplo, se ha dicho que en las democracias liberales, la administración de justicia asegura un control de los gobernantes a través del principio de legalidad y acaso a través del principio de constitucionalidad; es decir, estamos ante una función de control de los gobernantes por parte de la administración de justicia ${ }^{13}$.

También se ha establecido como función clásica del Poder Judicial o administración de justicia, el ejercicio de la potestad jurisdiccional, es decir, la declaración de existencia de un derecho cual es la tutela que una norma concede a un determinado interés, y la imposición mediante la fuerza coactiva de ese interés cuya tutela legalmente se ha declarado cierta ${ }^{14}$.

Ambas funciones de la administración de justicia son válidas e importantes; es absolutamente claro que la administración de justicia tiene como función decir el derecho, es decir, ejercer la potestad jurisdiccional. También es cierto que es función de la administración de justicia el control de los reglamentos mediante el principio de legalidad, y de las leyes mediante el principio de constitucionalidad, para evitar la arbitrariedad de los gobernantes ${ }^{15}$. Pero esto no agota el tema de las funciones de la administración de justicia; la administración de justicia es una de las bases fundamentales de la sociedad organizada, y es necesaria para que predomine la legalidad, para que se proporcione a cada

13 Maurice Duverger. Op.cit., p.167.

14 Esta función es recogida por varios procesalistas, entre ellos: Eduardo Couture. Fundamentos del derecho procesal civil. p. 40; Montero Aroca..., op.cit., p. 52-61; Ugo Rocco. Tratado de derecho procesal civil. p. 53 .

15 Esto es recogido también por la doctrina administrativa: Antonio Embid Irujo. "Potestad reglamentaria" p. 100 En RVAP no 29. 1991; Eduardo García de Enterría y Tomás Ramón Fernandez. Curso de derecho administrativo. 2r. p.437; Ramón Parada. Curso de derecho administrativo. 3t. Madrid: Marcial Pons, 1995. p.19-23. 
cual lo que le corresponde para que de esta manera no existan contiendas mayores y prevalezca lo que está arreglado a la ley y la razón. Reinando el principio del derecho. La función primordial de la administración de justicia, siguiendo este razonamiento, sería asegurar un adecuado funcionamiento del Estado, e indirectamente su estabilidad $y$ consolidación, y a través de esto lograr un mercado eficiente y el desarrollo.

\subsection{La función legitimadora de la administración de justicia}

No podemos analizar las funciones y la importancia de la administración de justicia por sí sola, en forma aislada. Para lograr una explicación adecuada y coherente es necesario estudiar la función y justificación del Estado, y ver el papel que juega la administración de justicia en esta función como parte del Estado.

La eficiencia del Estado y la de la administración de justicia se alimentan recíprocamente en una relación todo-parte de la siguiente manera: si el Estado es eficiente entonces la administración de justicia, como parte del Estado deberá dar prioridad el valor eficiencia. Y a la inversa, si la administración de justicia, como parte del Estado, prioriza el valor eficiencia, entonces contribuirá a lograr la eficiencia de la totalidad del Estado en el que está incluida.

Hemos determinado hasta ahora que la eficiencia es indispensable para que el Estado y la administración de justicia logren su objetivo final: el desarrollo a través del funcionamiento de un mercado eficiente. En este momento pasaremos a explicar qué importancia tiene haber determinado esto.

Partamos del individuo. Los individuos son interesados y tratan de maximizar su bienestar, el comportamiento de los individuos es racional en este sentido ${ }^{16}$. Según esto, los individuos siempre quieren mayores beneficios personales, pero la consecución de estos beneficios personales puede llevar a la aparición de costos sociales mayores que se configuren como externalidades, es decir, costos no asumidos por el agente productor ${ }^{17}$. Como cada individuo busca lograr mayores bene-

16 Santos Pastor. Op.cit., p. 157-158.

17 Alfredo Bullard. "Un mundo sin propiedad" p. 132. En Derecho. No 45 Diciembre 1991. p.131-157. 
ficios y como no asume los costos de sus acciones, entonces estos costos serán asumidos por la sociedad, es decir, por el resto de individuos; y así sucederá con cada individuo, lo que trae inseguridad, insatisfacción y finalmente conflicto. Estaríamos llegando a lo que Hobbes llama el estado de naturaleza, en el que los hombres luchan a muerte por conseguir lo que quieren ${ }^{18}$. Pero, como hemos dicho que los individuos son interesados y tratan de maximizar su bienestar, pronto se darán cuenta de que la solución de un estado de naturaleza es ineficiente $^{19}$, los costos sociales claramente superan a los beneficios personales obtenidos, reina la inseguridad y la anarquía, nadie puede vivir en paz y no existe la legalidad. Los hombres deciden pasar a una organización más eficiente, en donde se internalicen las externalidades. La internalización lleva a los individuos a tener en consideración los efectos que generan sus actos, lo que va a derivar en un resultado finalmente eficiente si los individuos se comportan racionalmente ${ }^{20}$. Es en este momento en que aparece el derecho como conjunto de reglas para lograr la internalización de externalidades y, junto con él, aparece el Estado, como ente garantizador del cumplimiento de ese conjunto de reglas. Así pues, la existencia del Estado es esencial para el crecimiento económico.

Vemos que el Estado existe para servir a los individuos y ayudarlos a conseguir la maximización de sus beneficios, es decir, para ayudarlos a ser eficientes. También sabemos que el Estado tiene un objetivo final que es permitir el funcionamiento de un mercado eficiente donde se logre el desarrollo, lo que justamente es lo mismo que conseguir la maximización del bienestar de su población. Comprobamos entonces que hay una identidad de objetivos del Estado y de los individuos, y que un Estado eficiente logrará la eficiencia de sus pobladores. Pero, ¿qué sucede si el Estado no es eficiente? En este punto empiezan los problemas. Debemos recordar que un Estado maximizador de los beneficios tiene tres características esenciales: Primero, el Estado intercambia un grupo de servicios denominados protección y justicia,

18 Thomas Hobbes. Leviatán, o la Materia, Forma y Poder de una República Eclesiástica y Civil. 2a. Ed. México: FCE, 1984. p.100-117, 137-141.

19 Entendiendo por eficiencia toda situación en que lo que puede mejorar alguien es más que lo que han de empeorar otras personas para ello. Véase: Santos Pastor, op. cit., p. 158.

20 Alfredo Bullard. "Un mundo sin propiedad", p.158. 
por rentas ${ }^{21}$. Esto es lo que denominamos la función garantizadora del derecho por parte del Estado. Segundo, el Estado intenta actuar como un monopolista discriminador para maximizar su renta, separando cada grupo de gobernados e ideando derechos de propiedad para cada uno de ellos. Tercero, el Estado está limitado por el coste de oportunidad de sus gobernados, ya que siempre existen rivales potenciales para ofrecer la misma clase de servicios ${ }^{22}$.

Cuando el Estado es ineficiente, seguirá cobrando rentas y seguirá intentando maximizarlas, pero no brindará los servicios de protección y justicia, habrá dejado de cumplir su función garantizadora del derecho. La ausencia de la función garantizadora del Estado hace que los individuos vuelvan al estado de naturaleza, con el agravante de que ahora tenemos a un Estado que cobra a cambio de nada. A los individuos no les sirve de nada este Estado ineficiente, por el contrario, los perjudica, pues en vez de ser un agente promotor de seguridad jurídica crea inseguridad. Esta situación es a todas luces ineficiente y desligitima al Estado, hace entrar en juego la tercera característica del Estado: la limitación por el coste de oportunidad de sus gobernados. Según Hermann Heller, en cuanto se pierde la fe en la legitimidad de la existencia del Estado concreto o del Estado como institución, puede estimarse que ha llegado su fin, ya sea para el pueblo del Estado, ya para el correspondiente círculo de cultura, ya incluso para toda la humanidad. En este sentido el Estado vive de su justificación ${ }^{23}$.

Los individuos pierden la fe en el Estado y van abandonándolo paulatinamente conforme toman conciencia que es un estorbo y no una solución. La falta de apoyo al Estado hace que este obtenga cada vez menores recursos para satisfacer sus necesidades y brindar los pocos servicios que aún da; para intentar llenar este vacío, el Estado aumenta las cargas sobre sus ciudadanos, quienes sienten rechazo hacia esta actitud y buscan escapar a ella en mayor número; la consecuencia es menores ingresos para el Estado, mayor ineficiencia, menores beneficios y mayor inseguridad. Todo este proceso se va autorreplicando hasta llegar a lo inevitable: el colapso del Estado ${ }^{24}$.

21 Douglas North. Op.cit., p. 38.

22 Ibid., p. 39.

23 Hermann Heller. Teoría del Estado. México: Fondo de Cultura Económica, 1985, 1985. p. 235 .

24 Este razonamiento es utilizado, junto con otras variables, para explicar la crisis del 
La administración de justicia, como parte del Estado, puede contribuir a lograr la eficiencia de la totalidad del Estado, pues es un elemento fundamental en el proceso de brindar los servicios de protección y justicia por parte del Estado, cumple por ello una función legitimadora del Estado, garantizando la consecución de los fines intermedios necesarios para llegar al objetivo final: el desarrollo en un mercado eficiente.

\section{Problemática de la administración de justicia en el Perú.}

En esta parte del trabajo trataremos de dar algunas aproximaciones sobre los principales problemas de la administración de justicia en el Perú y sobre sus causas fundamentales, a partir de un análisis histórico.

\subsection{Identificación del problema principal de la administración de justicia en el Perú.}

La administración de justicia en el Perú se encuentra en crisis, es ineficiente y no garantiza la propiedad privada y la riqueza, pues no da seguridad jurídica ya que sus fallos no son predecibles. A todas luces se puede ver que el problema principal de la administración de justicia en el Perú es la corrupción. La corrupción es fuente y consecuencia a la vez de la ineficiencia del Poder Judicial. Se podría decir que son problemas de la administración de justicia la lentitud de los procesos, la falta de predicibilidad de los fallos judiciales, y la falta de preparación de los jueces, entre otros. Pero todos estos problemas son secundarios y ceden el lugar principal a la corrupción, la cual puede explicarlos a todos y se alimenta de ellos a la vez. Esta corrupción no debe ser entendida en la forma tradicional como la realización de acciones moralmente malas, la moral es irrelevante para este enfoque; sino que debe ser entendida como el intento de maximizar racionalmente la utilidad individual en función a una base de información deficiente o errónea. La corrupción es una consecuencia de la falta de información adecuada para tomar decisiones eficientes; es un caso de confusión que no deja

\footnotetext{
Imperio Romano. Véase: Roger Remondon. La crisis del Imperio Romano: de Marco Aurelio
} a Anastasio. Barcelona: Labor, 1967. 
tomar decisiones adecuadas y empuja a los individuos a tomar decisiones ineficientes.

\subsection{Causas de la crisis en la administración de justicia}

Para entender la crisis en la administración de justicia es necesario senalar como causa fundamental de ella que el propio hombre peruano se encuentra confundido debido a una información deficiente que le hace creer que ser corrupto es ser astuto y le permite maximizar sus beneficios, esto de acuerdo al principio de estabilidad de las preferencias es la explicación de la corrupción; la moral no tiene nada que ver, los individuos no son esencialmente buenos ni esencialmente malos, solamente son maximizadores racionales de su propia utilidad. Todo depende de la información disponible en el mercado para que los individuos tomen las decisiones adecuadas. Si los propios hombres no son capaces de distinguir qué cosa es realmente eficiente y conveniente para ellos y qué cosa es ineficiente -aunque no lo parezca a primera vista-, entonces ¿de dónde podrían salir los hombres honestos que necesita la administración de justicia? Con esto no estamos afirmando que la totalidad de individuos que componen la sociedad peruana son corruptos, sino que existe una gran cantidad que lo es en diversos grados. Además debemos recordar que los individuos son interesados y buscan maximizar sus beneficios; como esos individuos conocen que la administración de justicia está en crisis y es corrupta -pues esta información sí se encuentra disponible en abundancia en el mercado-, entonces la mayoría de individuos considerará que el costo personal -el estigma- es superior a los beneficios que obtendrán, y optarán por no integrar la administración de justicia. Esto sucederá con los individuos más capacitados; los individuos que consideran que los beneficios -de cualquier tipo- son superiores a los costos, optarán por ingresar a la administración de justicia. Así vemos que la falta de cuadros humanos es causa de la crisis en la administración de justicia, y en la mayor parte esta falta de cuadros humanos es causa de la crisis en la administración de justicia, y en la mayor parte esta falta de cuadros humanos es consecuencia de la misma corrupción de la administración de justicia y de la sociedad en general. Estamos en el círculo vicioso de la corrupción, en el que la corrupción de la administración de justicia es causa y consecuencia a la vez de la falta de material humano. 
La crisis económica, la falta de acción o pasividad de la sociedad civil, la falta de voluntad política de consolidar la administración de justicia, la falta de seguridad personal para los magistrados, la falta de una infraestructura adecuada para el Poder Judicial, y la existencia de jueces sin vocación son también causas de la crisis en la administración de justicia; esto es indudable: la confusión conceptual del individuo peruano, y no del peruano actual sino del individuo peruano de siempre.

Todas las pequeñas causas secundarias mencionadas se van encadenando una tras otra para ir formando la causa fundamental. Veamos el proceso.

Existe crisis económica porque en la sociedad peruana han existido graves y profundas desigualdades -esto también es consecuencia de la falta de información, porque los individuos privilegiados suponían que las desigualdades eran la mejor manera de maximizar su propia utilidad, cosa falsa, pues la mejor manera de maximizar la utilidad es ampliar la torta de la riqueza al máximo posible. La crisis económica existe desde la época en que el Perú pertenecía al imperio español, esto es recogido por reconocidos historiadores ${ }^{25}$, uno de los cuales incluso afirma que los habitantes del virreinato peruano, sobre todo los de Lima, se vanagloriaban absurdamente porque creían ser la joya de la Corona Española en América, cosa que no era cierta en absoluto ${ }^{26}$. Esta impresión fue recogida por testigos presenciales de la época que testifican la decadencia del virreinato peruano, entre ellos el comandante de la nave rusa Kamchatka, Vasilii M. Golovnin, quien llegó al Callao en $1818^{27}$, y el inglés William Bennet Stevenson, quien vivió en territorio de la América del Sur española de 1804 a $1827^{28}$.

La crisis económica nos acompaña a lo largo de toda la historia del Perú republicano: en el período post-independencia entre la plata y el

25 Véase: Timothy Anna. The fall of the royal government in Peru. Lincoln: University of Nebraska Press, 1990; Heraclio Bonilla y Karen Spalding. La independencia en el Perú; John R. Fisher. Gobierno y sociedad en el Perú colonial. El régimen de las intendencias; John Lynch. Las revoluciones hispanoamericnas 1808-1826.

26 Timothy Anna. Op.cit., p.1-2.

27 Ibid, p. 2-3.

28 Ibid, p. 3 
guano $(1826-1850)^{29}$, en el período del guano ${ }^{30}$. El siglo XIX se cierra con una gran tarea por cumplir, la reconstrucción nacional. La anarquía y la guerra civil durarán con intermitencias hasta 1895 cuando Nicolás de Piérola asciende al poder y se inaugura la "República Aristocrática". Esta tiene un Estado mejor asentado pero aún enfrenta la escasez y la crisis económica por lo que entra en decadencia y es cancelada $^{31}$. El régimen de la Patria Nueva instaurado por Leguía intentó llevar a cabo una modernización del país, pero terminó siendo destruido por la crisis económica de $1929^{32}$. Los sucesivos gobiernos a partir de 1930 hasta 1990 fueron en su mayor parte administradores de la crisis económica peruana y fueron además herederos del aparato burocrático estatal dejado por Leguía, quien puede ser considerado el fundador del modelo de Estado que ha regido en el Perú desde 1920 hasta la década de 1990, con las modificaciones producidas en la década de 1970 por el gobierno militar, cuando se absolutizó torpemente al Estado $^{33}$.

La crisis económica siembra descontento entre los individuos, pues estos perciben que el Estado no les ayuda a maximizar sus beneficios una información muy peligrosa-; el Estado va perdiendo legitimidad. El Estado sabe esto e intenta solucionar la crisis, pero se da cuenta de que no cuenta con los recursos necesarios para hacerlo. El remedio sería elevar la captación de recursos a través de mayores cargas para la

29 Véase: Paul Gootenberg. Between silver and guano. Commercial policy and the State in postindependence Peru. Princeton: Princeton University Press, 1991.

30 La crisis generada por el despilfarro y endeudamiento de la era del guano provocarán la falta de recursos del Estado peruano y su falta de capacidad defensiva, lo que lo llevará a la derrota y al colapso. Véase: Jorge Basadre. "Antecedentes de la Guerra con Chile". En Historia del Perú. Tomo VII. Ed. Juan Mejía Baca; Heraclio Bonilla. Guano y burguesía en el Perú. Lima: IEP; Carmen McEvoy. Un proyecto nacional en el siglo XIX.; Alfonso Quiroz. La deuda defraudada. Lima: INC.

31 Aunque no afronta graves crisis económicas como las del siglo XIX, la República Aristocrática no está libre de sufrir los embates de la crisis económica y de la escasez, sobre todo por las desigualdades sociales producidas por el sistema de dominación ineficiente que imperaba en la época. Véase: Manuel Burga y Alberto Flores Galindo. Apogeo y crisis de la República Aristocrática; Julio Cotler. Clases, Estado y Nación en el Perú. Ga. de. Lima: IEP, 1992. p.119-184.

32 Julio Cotler. Op. cit., p. 185-226.

33 Esta opinión sobre el gobierno de Leguía se encuentra con mayor detalle en: Baltazar Caravedo Molinari. "Economía, producción y trabajo. (Perú, siglo XX)" p.216-231. En Historia del Perú. Tomo VIII. Ed. Juan Mejía Baca. 
población; esto es entrar a un juego peligroso, pues si el Estado no consigue solucionar la crisis, el descontento aumentará porque habrán aumentado los costos para los individuos y los beneficios serán los mismos o habrán disminuido. El Estado es un Estado ineficiente, y volverá a intentar solucionar la crisis de la misma manera, autorreplicando la crisis económica y perdiendo más legitimidad. Los individuos tratarán de eludir las cargas del Estado, éste las aumentará y presionará para conseguirlas por lo que se fomentará la corrupción. La corrupción estará presente en los individuos que intentan eludir las cargas para el sostenimiento del Estado a cualquier precio, y en los propios funcionarios del Estado que se prestarán a los deseos de la población a cambio de beneficios personales.

En el Perú, la corrupción y la crisis económica existen aún antes de que se fundara el Estado peruano independiente, según testimonios de la época, aun los virreyes más probos que llegaban al Perú con buenas intenciones, sucumbían al sistema, que todo lo penetraba, de sobornos, corrupción, influencia y mala administración por los que el Perú se había vuelto notorio a mediados del siglo XVIII ${ }^{34}$.

La corrupción existente en el Perú ha sido una de las causas generadoras de la crisis económica en el Perú, si bien no es la única ${ }^{35}$, y a la vez se agrava a causa de esa misma crisis: es el mecanismo de alimentación recíproca corrupción-crisis económica.

La administración de justicia en el Perú se ha visto afectada también por el vicio de la corrupción que afecta a nuestra sociedad, directamente y a través de la crisis económica que esta provoca. Al ser parte del Estado, la administración de justicia se ve perjudicada por la falta de recursos del Estado, siéndole negadas una mejor infraestructura y mejores incentivos económicos traducidos en buenos sueldos, lo que provocará que los mejores elementos de la sociedad se sientan ahuyentados de la administración de justicia. El estar privada de los mejores elementos de la sociedad hace que la administración de justicia no pueda actuar en forma eficiente, sus resoluciones no son predecibles en absoluto, no logra garantizar la propiedad privada ni la riqueza, y no cumple su función legitimadora del Estado, pues no ayuda a conseguir el desarrollo.

34 John R. Fisher. Op.cit., p. 22

35 Algunas causas de la crisis económica a fines del Perú colonial se encuentran en: Timothy Anna. Op.cit., p. 1-25. 
Como la administración de justicia en el Perú no cumple su función legitimadora del Estado, el Estado peruano se ve afectado por la ineficiencia de su Poder Judicial, y a su vez se vuelve más eficiente porque su sociedad civil trata de escapar a las cargas que impone, lo que genera mayor corrupción y más ineficiencia tanto para el Estado como para la administración de justicia. Este proceso de desestructuración estatal se produjo en el Perú y estuvo a punto de hacer colapsar al Estado peruano a fines de la década de 1980. El Estado peruano contaba con una administración de justicia tan ineficiente que generaba tanta corrupción de la que se alimentaba a su vez, como en un círculo vicioso, y no lograba cumplir su función legitimadora del Estado. El Estado peruano era cada vez más ineficiente como consecuencia de la ineficiencia de su administración de justicia y a la vez alimentaba esta ineficiencia de su administración de justicia. El Estado peruano y su administración de justicia, hacia fines de la década de 1980 iban camino al colapso y la desintegración como consecuencia de su propia corrupción que ellos mismos alimentaban ${ }^{36}$.

3. Reforma de la administración de justicia en una economía de mercado

El modelo económico adoptado en el Perú de los '90 es el de una economía de mercado, por lo cual pasaremos a analizar cuáles son los objetivos del Estado según este modelo y cómo puede ayudar la administración de justicia a conseguirlos, y el modo de implantar esta reforma.

3.1. Objetivos del Estado en una economía de mercado: el papel que debe desempeñar la administración de justicia.

Nuestro modelo teórico del Estado en una economía de mercado nos indica que su objetivo final es lograr el desarrollo en un mercado efi-

36 Este proceso de desintegración se vio agravado por la presencia del fenómeno terrorista y la guerra interna. Ahora tenemos las dos variables para explicar la caída de un Estado: la ineficiencia de su propio aparato y la guerra. Este proceso de desintegración es analizado para el caso del Imperio Romano en: Roger Remondo. Op.cit. 
ciente, o para decirlo de otro modo, el orden y el progreso. Objetivos intermedios del Estado son el promover la acumulación de riqueza de sus pobladores, asegurar la propiedad privada y brindar seguridad jurídica. Para ello se necesitan reglas claras y una aplicación eficiente de esas reglas a los casos concretos. Por ello, para que un Estado sea eficiente se requiere una administración de justicia eficiente. Y a la vez, para que se pueda llegar a una administración de justicia eficiente, es necesario que exista la voluntad política de conseguirla ${ }^{37}$.

El Estado peruano se ha planteado como metas inmediatas el conseguir captar inversiones extranjeras para lograr la acumulación de riqueza y el desarrollo del país. Los inversionistas extranjeros, como todos los individuos, son interesados y buscan maximizar sus beneficios; por ello es esencial que el Estado les otorgue una adecuada protección y seguridad para sus inversiones, haciendo que los beneficios sean mayores a los costos, pues todos los individuos tienen aversión al riesgo, esto quiere decir que los inversionistas no tomarán en cuenta la magnitud racional del riesgo, sino que tenderán a exagerarlo, deformando los presupuestos de base mediante los cuales se orientan las decisiones económicas ${ }^{38}$. La falta de seguridad desalentará la llegada de inversiones, provocará la acentuación de la pobreza y hará imposible superar la crisis.

Para la atracción de inversiones extranjeras es necesario contar con un Estado eficiente, legítimo, y por ello consolidado, pues es el único que puede brindar los servicios de seguridad que piden los inversionistas. Asimismo, para conseguir este objetivo es necesario contar con una administración de justicia eficiente, pues es el instrumento que el Estado utilizará para garantizar el respeto cabal y oportuno de las reglas de juego del mercado, la libre competencia, y además, cumplirá la función legitimadora del Estado, lo que reforzará el clima de confianza de los inversionistas.

37 Esta voluntad polírica no sólo es necesaria para conseguir una administración de justicia eficiente sino para la consecución de reglas claras que permitan la propiedad privada absoluta, necesarias también para crear un clima atractivo para las inversiones y la acumulación de riqueza. Al respecto, véase el excelente análisis en: Felipe Osterling Parodi y Mario Castillo Freyre. Tratado de las obligaciones. Para leer el Código Civil. Vol. XVI. Primera Parte. Tomo I. p.317-501.

38 Alfredo Bullard. "Un mundo sin propiedad", p.142-143. 


\subsection{Hacia una modernización de la administración de justicia}

El beneficio de una reforma judicial no es el juez sino el ciudadano; el propósito de la reforma es facilitar a la administración de justicia un mejor servicio al ciudadano y a los agentes económicos en la sociedad. El principal obstáculo para este propósito, y uno de los principales obstáculos para el comercio, la inversión y el desarrollo, es la separación que existe en la mayoría de países en desarrollo entre la ley tal como se promulga y la forma en que la sociedad se conduce y la economía funciona en la vida real ${ }^{39}$. De todos los actores legales el juez es el único que no puede dejar de enfrentar esta contradicción.

\subsubsection{El contexto legal.}

Para iniciar una modernización de la administración de justicia es importante crear un adecuado marco legal para realizarla. Aparte de este necesario marco legal para reestructurar y afianzar a la propia administración de justicia, es necesario darle un adecuado marco legal acorde con los nuevos objetivos del país, es necesario contar con reglas claras y simples, que sean de real utilidad; no se deben crear instituciones que luego deberán ser desreguladas y que aumenten los costos del sistema o que aumenten la diferencia entre el derecho y la realidad ${ }^{40}$.

Son necesarias reformas legales tanto en el nivel objetivo como sustantivo. A nivel objetivo se encuentra la búsqueda de eficiencia y simplificación de los procesos judiciales y la dación de normas para la selección y mantenimiento de personal honesto y eficiente para la administración de justicia. En el nivel sustantivo se encuentra la modificación del marco legal en el que se mueve el país para adecuarlo a los nuevos objetivos del Estado en una economía de mercado.

39 Sobre el tradicional divorcio entre el derecho y la realidad en el Perú, véase: William Griffiths Rivero. Los hechos y los textos en el derecho político peruano. 1970. Tesis de bachiller, Pontificia Universidad Católica del Perú. Lima, 1970.

40 Sobre la desregulación y la reconciliación del derecho con la realidad, véase: Hernando de Soto. El Otro Sendero. La Revolución informal. Bogotá: ILD, 1989. p.307. 


\subsubsection{La administración del sistema}

\section{a. Administración del sector:}

En esta área es necesario determinar racionalmente la distribución territorial y por materias del Poder Judicial, es decir, se debe determinar el número de tribunales y de jueces de acuerdo a la población y al número de casos.

\section{b. Cuestiones de personal:}

Dentro de estas cuestiones resaltan como prioridades la selección y nombramiento de jueces y de auxiliares de justicia. Esta es la parte más delicada de la reforma, pues es necesario captar a los mejores elementos de la sociedad para lograr una mejora real; es necesaria toda una reingeniería humana. Para hacerlo es necesario dar incentivos económicos adecuados y señales claras de voluntad de reforma integral, para que los beneficios de pertenecer a la administración de justicia sean superiores a los costos y los mejores elementos de la sociedad ingresen al servicio.

\section{c. Relaciones de los jueces:}

En las relaciones de los jueces con los demás poderes del Estado y con otras instancias al interior del mismo poder judicial debe primar el principio de la independencia judicial ${ }^{41}$. Esta independencia es necesaria para que el juez pueda decidir honestamente y sin presiones; es necesaria para garantizar honestidad y eficiencia, partiendo del supuesto de que contamos con los individuos más calificados en la administración de justicia. Los jueces deben ser inmunes a cualquier tipo de presión, ya sea del interior del Estado o del exterior, con lo cual nos referimos a la influencia de la prensa y la actitud de los litigantes.

41 Alberto M. Binder. Introducción al Derecho Procesal Penal. Bs. Aires: Ad Hoc, 1993. p. 145-146. 


\section{d. Administración de los casos:}

La designación de los casos debe realizarse de una manera totalmente aleatoria para reducir al mínimo las posibilidades de corrupción y arreglos entre abogados y jueces. El juez debe ser quien dirija efectivamente el proceso, para esto es necesario reducir la carga de casos que soporta; es muy importante que sea el mismo juez quien redacte la sentencia, pues sino estaríamos ante la violación de la garantía del juicio previo en materia penal, y del debido proceso en general ${ }^{42}$.

\subsubsection{El costo económico de la justicia.}

Es importante establecer un porcentaje adecuado y suficiente del presupuesto nacional para el Poder Judicial, sino será imposible llevar a cabo una reforma integral de la administración de justicia. La eficiencia de la administración de justicia puede ser causa y consecuencia a la vez de la asignación de recursos adecuados por parte del Estado.

Los litigantes deben asumir su parte en el costo económico de la justicia; pero solamente deben asumir los costos establecidos en la ley, y deben obtener por ello un servicio eficiente, es decir, fallos justos y predecibles. Es necesario acabar con los costos ocultos del sistema derivados de la corrupción de la administración de justicia para legitimar el sistema.

Una administración de justicia eficiente no generará costos indirectos para la sociedad, en cambio, uno ineficiente sí los generará bajo la forma de atraso y empobrecimiento: el resultado final es la deslegitimación del Estado y la entrada en el círculo vicioso de la corrupción y la pobreza.

\subsubsection{Métodos de solución alternativas de controversias}

El Estado debe dar normas que permitan crear un marco de incentivos que haga que los individuos se comporten de modo eficiente, que haga máximo el bienestar social; esto es crucial para cualquier sociedad ${ }^{43}$.

42 Alberto M. Binder. Op.cit, p.117-118.

43 Santos Pastor. Op.cit., p.156-157. 
La redistribución a través de normas legales tiene el inconveniente de que en numerosas ocasiones sus efectos distributivos buscados apenas pueden llevarse a cabo, y en otros casos en que sí puede tener consecuencias distributivas sustanciales, su efectividad se ve limitada porque es menos preciso y sistemático que otros medios alternativos ${ }^{44}$.

Si existen medios alternativos más precisos que la administración de justicia estatal el Estado, haciendo primar el valor eficiencia, debe permitir su uso a los particulares ${ }^{45}$. En este caso es posible aplicar el Teorema de Coase, según el cual, el Estado deberá intervenir si los beneficios netos de su actuación son mayores que los de su no intervención. Los particulares podrían llegar a acordar una solución eficiente ante efectos externos mediante la negociación, con lo cual la intervención del Estado puede carecer de sentido.

\section{3. ¿Todo o nada u objetivos parciales?}

Sabemos que el objetivo del Estado es permitir el funcionamiento de un mercado eficiente para lograr el desarrollo. Ya en el pasado se había intentado lograr el desarrollo, pero siempre se fracasó debido a la confusión de conceptos que imperaba y que no permitía definir el rol del Estado ni los medios de lograr estos objetivos.

Hoy día la economía de mercado adoptada como modelo por el Estado ha permitido lograr una claridad conceptual jamás vista en la historia del Perú. Parafraseando a Kant, nos atrevemos a decir que la economía de mercado es la liberación del hombre de su culpable incapacidad. La incapacidad significa la imposibilidad de servirse de su inteligencia sin la guía de otro. Esta incapacidad es culpable porque su causa no reside en la falta de inteligencia sino de decisión y valor para servirse de ella sin la tutela de otro. ¡Ten el valor de servirte de tu propia razón!: he aquí el lema de la economía de mercado ${ }^{46}$.

44 Ibid., p. 160.

$45 \mathrm{Al}$ respecto es importante el paso adelante que significa la nueva ley de arbitraje, que permite la efectivización en la práctica de este medio alternativo y lo deja listo para ser utilizado por los particulares. Véase: Ley 26572. Normas Legales. El Peruano. 5 de enero 1996. P. $136635-136650$.

46 Kant define en estos términos a la llustración, nosotros adaptamos su discurso a nuestra época. Véase: Immanuel Kant. Filosofía de la historia. México: FCE, 1979. p. 25. 
Hemos establecido que un Estado ineficiente es causa y consecuencia a la vez de la corrupción, y que es un Estado deslegitimado. Para paliar esto, en el Perú, el Estado buscó convertirse en una suerte de padre o protector de los individuos, generando con ello mayor ineficiencia y corrupción; los individuos a su vez trataban de maximizar sus beneficios personales obteniendo lo que podían de ese Estado paternalista, sin importarles el medio, pues ellos no sentían ningún respeto hacia ese Estado deslegitimado y en vías de extinción. La oscuridad conceptual no dejaba ver ni a los individuos ni al Estado lo crítico de la situación y el perjuicio que acarreaba para ambos; para el Estado porque implicaba su desaparición, y para los individuos porque suponía la vuelta al estado de naturaleza. La economía de mercado ha venido a establecer estos conceptos claros, liberando a los hombres y al Estado de sus errores, y haciendo ver que el rol del Estado es el de agente de seguridad y protección jurídica, de garantizador del orden y el progreso, a través de la acumulación de riqueza realizada por los particulares en el mercado y no por él directamente.

En este contexto, la razón nos indica que estamos en un momento en que sólo cabe el todo o nada, y que cualquier objetivo parcial será igual a no haber logrado nada. Es necesario arriesgarse a reformar y modernizar integralmente a la administración de justicia para adecuarla al nuevo momento histórico que vive el Perú, y no sólo la administración de justicia, sino modernizar la totalidad del Estado, pues ambas reformas se implican una a otra y no son posibles la una sin la otra. Así como hemos visto que la corrupción y la crisis se autorreplican y se alimentan mutuamente, también la reforma y la eficiencia de la administración de justicia y del Estado se autorreplican y alimentan mutuamente. Es necesario que el Estado siga la enseñanza de la economía de mercado y se libere de su culpable incapacidad, llegando a la eficiencia total, y por tanto al desarrollo del Perú.

\section{Conclusiones}

1. La administración de justicia es esencialmente un servicio. Este servicio es prestado por el Estado a la comunidad mediante la solución de controversias, para mantener la paz social y facilitar el desarrollo económico. 
2. La eficiencia del Estado y la de la administración de justicia se alimentan recíprocamente en una relación todo-parte.

3. La administración de justicia cumple una función legitimadora del Estado.

4. El problema principal de la administración de justicia es la corrupción -como una suerte de confusión debido a información deficiente, de acuerdo al principio de estabilidad de las preferencias-, la cual es fuente y consecuencia a la vez de la ineficiencia y la crisis del Poder Judicial.

5. La crisis económica ha existido a lo largo de toda la historia del Perú, al igual que la corrupción. La corrupción y la crisis económica se alimentan mutuamente.

6. El beneficiario de una reforma judicial no es el juez sino el ciudadano.

7. La cuestión de selección de personal es vital para una real modernización de la administración de justicia; es necesaria una reingeniería humana. Esto está ligado a la propia eficiencia del sistema que se autorreproducirá y redundará en mayores beneficios que costos para sus integrantes.

8. Si existen medios alternativos más precisos y sistemáticos que el servicio estatal, se debe impulsar su uso haciendo primar el valor eficiencia.

9. En materia de modernización del Estado y de la administración de justicia sólo cabe el todo o nada. Cualquier objetivo parcial sería un fracaso.

\section{Bibliografía}

Anna, Timothy.

1990 The fall of the royal government in Peru. Lincoln: University of Nebraska Press, 1990. 238p.

BASADRE, Jorge.

"Antecedentes de la Guerra con Chile". En Historia del Perú. Ed. Juan Mejía Baca. Vol. 7. 
BECKeR, Gary S.

1980 "El Enfoque Económico del Comportamiento Humano". En Información Comercial Española. No 557 Enero 1980.

BECKer, Gary S.

1962 "Irrational Behavior and Economic Theory". En Journal of Political Economy. Vol. 70 No 1. 1962.

BINDER, Alberto M.

1993 Introducción al derecho procesal penal. Bs. Aires: Ad Hoc.

Bonilla, Heraclio.

1974 Guano y burguesía en el Perú. Lima: IEP, 1974. 171p.

Bonilla, Heraclio y Karen Spalding.

La independencia en el Perú. Lima: IEP.

Buchanan, James y Gordon Tullock.

1965 The Calculus of Consent. Ann Arbor: The University of Michigan Press, 1965. 361p.

Bullard, Alfredo.

"iAl fondo hay sitio! ¿Puede el Teorema de Coase explicarnos el problema del Transporte Público?" En Thémis. Lima. No 21 .

BulLaRd, Alfredo.

1991 "Un mundo sin propiedad". En Derecho. No 45. Diciembre 1991. P.131-157.

Burga, Manuel y Alberto Flores Galindo.

1984 Apogeo y crisis de la República Aristocrática. Ediciones Rickhay Perú, Lima.

Calabresi, Guido.

1984 "First Party, Third Party, and Product Liability System: Can Economic Analysis of Law Tell Us Anything About Them?" En Iowa Law Review. Vol. 69 (Mayo 1984). 
Calabresi, Guido y Douglas Melamed.

"Reglas de la Propiedad, de la responsabilidad e Inalienabilidad: Un vistazo a la Catedral". En Thémis. Lima. No 21.

Caravedo Molinari, Baltazar.

"Economía, producción y trabajo (Perú, siglo XX)". En Historia del Perú. Ed. Juan Mejía Baca. V.8.

CARRE DE Malberg.

1948 Teoría General del Estado. México: FCE, 1948.

COASE, Ronald.

1960 "The Problem of Social Cost". En Journal of Law and Economics. Chicago. Vol. 3. 1960.

Cotler, Julio.

1992 Clases, Estado y Nación en el Perú. 6a de. Lima: IEP, 407p.

Couture, Eduardo.

1948 Fundamentos del Derecho procesal civil. Bs. Aires: Depalma.

Del Vecchio, Giorgio.

Teoría del Estado.

Duverger, Maurice.

1970 Instituciones políticas y derecho constitucional. 5a. ed. Barcelona: Ariel, 639p.

EMBID Irujo, Antonio.

1991 "Potestad Reglamentaria" En R.V.A.P. № 29.

FISHER, John R.

1981 Gobierno y sociedad en el Perú colonial. El Régimen de las intendencias. Lima: Pontificia Universidad Católica del Perú, 280p. 
Garcí de Enterria, Eduardo y Tomás Ramón Fernandez.

Curso de Derecho Administrativo. 2v.

GoOTENBerg, Paul.

1991 Between silver and guano. Commercial Policy and the State in postindependence Peru. Princeton: Princeton University Press, 158 p.

Griffiths Rivero, William.

1970 Los hechos y los textos en el derecho político peruano. Tesis de bachiller. Pontificia Universidad Católica del Perú. Lima.

HeLler, Hernann.

1985 Teoría del Estado. México: FCE.

Hobies, Thomas.

1984 Leviatán, o la Materia, Forma y Poder de una República Eclesiástica y Civil. 2a. De. México: FCE.

KANT, Immanuel.

1979 Filosofía de la historia. México: FCE.

LEY No 26572.

1996 "Normas Legales". El Peruano. 5 de enero.

LYNCH, John.

1989 Las revoluciones hispanoamericanas 1808-1826. 5a. De. Barcelona: Ariel, 382p.

McEvoy, Carmen.

1994 Un proyecto nacional en el siglo XIX. Manuel Pardo y su visión del Perú. Lima: Pontificia Universidad Católica del Perú, 354p.

Montero Aroca, Juan y Manuel Ortells Ramos.

1987 Derecho Jurisdiccional. Parte General. Barcelona: Librería Bosch. 
NoRTH, Douglas.

1981 Estructura y cambio en la historia económica. Madrid: Alianza Editorial.

Osterling Parodi, Felipe y Mario Castillo Freyre.

1994 Tratado de las obligaciones. Biblioteca Para Leer el Código Civil. Vol. XVI. Primera Parte. Lima: Pontificia Universidad Católica del Perú, 7v.

OsZLAK, Oscar.

1994 "Formación histórica del Estado en América Latina". En Blancas, Carlos, Landa, César y Marcial Rubio. Derecho Constitucional General. 4a. ed. Lima: Pontificia Universidad Católica del Perú, 2v.

Parada, Ramón.

1995 Curso de Derecho Administrativo. Madrid: Marcial Pons, $3 v$.

PASTOR, Santos.

1984 "Una introducción al análisis económico del Derecho". En Hacienda Pública Española. No 89. P.153-177.

POSNER, Richard A.

1992 Economic Analysis of Law. 4a.ed. Boston: Little, Brown and Company.

PosNer, Richard A.

1981 The Economics of Justice. Cambridge: Harvard University Press.

Quiroz, Alfonso.

1987 La deuda defraudada. Lima: INC, 219p.

REMONDON, Roger.

1967 La crisis del Imperio Romano: de Marco Aurelio a Anastasio. Barcelona: Labor. 
Rocco, Ugo.

Tratado de derecho procesal civil.

Soto, Hernando de.

1989 El Otro Sendero. La revolución informal. Bogotá: ILD, $317 \mathrm{p}$.

STIGleR, George J. y Gary S.BeCKer.

1977 "De Gustibus Non Est Disputandum". En American Economic Review. Vol. 67 No 2 (marzo).

TORRES LOPEZ, Juan.

1987 Análisis Económico del Derecho. Madrid: Tecnos. 